\title{
Resveratrol protects astrocytes against traumatic brain injury through inhibiting apoptotic and autophagic cell death
}

\author{
C-J Lin ${ }^{1,2,7}$, T-H Chen ${ }^{3,7}$, L-Y Yang ${ }^{1,4}$ and C-M Shih ${ }^{\star, 1,2,5,6}$
}

Traumatic brain injury (TBI) is often caused by accidents that damage the brain. TBI can induce glutamate excitotoxicity and lead to neuronal and glial cell death. In this study, we investigated the mechanism of cell death during the secondary damage caused by TBI in vivo and in vitro, as well as the protective effect of resveratrol (RV). Here we report that glycogen synthase kinase-3 $\beta$ (GSK-3 $\beta$ ) activation and microtubule-associated protein light chain 3 processing were induced in rat brains exposed to TBI. In the in vitro TBI model, apoptotic and autophagic cell death were induced through glutamate-mediated GSK-3 $\beta$ activation in normal CTX TNA2 astrocytes. The GSK-3 $\beta$ inhibitor SB216763 or transfection of GSK-3 $\beta$ small-interfering RNA increases cell survival. By contrast, overexpression of GSK-3 $\beta$ enhanced glutamate excitotoxicity. Administration of RV reduced cell death in CTX TNA2 astrocytes by suppressing reactive oxygen species (ROS)-mediated GSK-3 $\beta$ activation, the mechanism by which RV also exerted protective effects in vivo. Mitochondrial damages, including the opening of mitochondrial permeability transition pore (MPTP) and mitochondrial depolarization, were induced by glutamate through the ROS/GSK-3 $\beta$ pathway. Moreover, cyclosporine A, an MPTP inhibitor, suppressed mitochondrial damage and the percentages of cells undergoing autophagy and apoptosis and thereby increased cell survival. Taken together, our results demonstrated that cell death occurring after TBI is induced through the ROS/GSK-3 $\beta /$ mitochondria signaling pathway and that administration of RV can increase cell survival by suppressing GSK-3 $\beta$-mediated autophagy and apoptosis. Therefore, the results indicated that resveratrol may serve as a potential therapeutic agent in the treatment of TBI.

Cell Death and Disease (2014) 5, e1147; doi:10.1038/cddis.2014.123; published online 27 March 2014

Subject Category: Neuroscience

Traumatic brain injury (TBI) is defined as an injury caused by a blow or jolt to the head or a penetrating head injury that disrupts the normal function of the brain. ${ }^{1} \mathrm{TBI}$, which chiefly occurs because of traffic accidents, falls, or as a result of violence, is a leading cause of morbidity and mortality worldwide. ${ }^{2,3}$ TBI induces primary damage, including hematomas, contusions, ischemia, and diffuse swelling, which results in neurological impairment. Primary damage can initiate secondary brain damage such as neurotransmitter release, oxidative stress, calcium-mediated damage, mitochondrial dysfunction, and inflammation, and thereby lead to cell death within a few days or weeks. ${ }^{2,4}$

Glutamate is the major excitatory neurotransmitter in neuronal and glial cells of the mammalian central nervous system (CNS). ${ }^{5}$ However, after TBI, glutamate increases to toxic levels, causing further damage and leading to 'glutamate excitotoxicity'. ${ }^{6}$ Glutamate can induce cortical neuron apoptosis through calcium overload-induced calpain activation. ${ }^{7,8}$ In addition to damaging neurons, glutamate can damage glial cells, such as astrocytes and oligodendrocytes. ${ }^{9}$ Astrocytes are the most abundant glial cells in the CNS and can transport nutrients, hold neurons, and participate in neurotransmission. ${ }^{10}$ During brain injury, neuronal survival is strongly affected by the functions of astrocytes, such as glutamate uptake, release of glutamate, and the release of substrates for neuronal energy metabolism, ${ }^{11}$ suggesting that the damage caused to astrocytes following TBI adversely affects patient outcomes. Therefore, devising a strategy to protect astrocytes from cell death after TBI is crucial.

Glycogen synthase kinase-3 $\beta$ (GSK-3 $\beta)$ is a serine/ threonine kinase, the activation of which is indicated by phosphorylation at tyr216 or dephosphorylation at Ser9. ${ }^{12}$

\footnotetext{
${ }^{1}$ Graduate Institute of Medical Sciences, College of Medicine, Taipei Medical University, Taipei 110, Taiwan; ${ }^{2}$ Department of Biochemistry, College of Medicine, Taipei Medical University, Taipei 110, Taiwan; ${ }^{3}$ Division of Cardiovascular Surgery, Department of Surgery, Cathay General Hospital, Taipei 106, Taiwan; ${ }^{4}$ Department of Physiology, College of Medicine, Taipei Medical University, Taipei 110, Taiwan; ${ }^{5}$ Traditional Herbal Medicine Research Center, Taipei Medical University Hospital, Taipei 110, Taiwan and ${ }^{6}$ Center for Reproductive Medicine and Sciences, Taipei Medical University Hospital, Taipei 110, Taiwan

${ }^{*}$ Corresponding author: C-M Shih, Department of Biochemistry, School of Medicine, Taipei Medical University, 250 Wu-Hsing Street, Taipei, Taiwan; Tel: + 886227361661 \#3151; Fax: + 8862 27356689; E-mail: cmshih@tmu.edu.tw

${ }^{7}$ These authors contributed equally to this work.

Keywords: traumatic brain injury; resveratrol; glycogen synthase kinase-3 $\beta$; mitochondrial permeability transition pore; autophagy; apoptosis Abbreviations: $\Delta \Psi \mathrm{m}$, mitochondrial membrane potential; 3-MA, 3-methyladenine; BAF, bafilomycin A1; CNS, central nervous system; CsA, cyclosporine A; DCFHDA, 2,7-dihydrodichlorofluorescein diacetate; DHR123, dihydrorhodamine 123; GSK-3 $\beta$, glycogen synthase kinase- $3 \beta ; \mathrm{H}_{2} \mathrm{O}_{2}$, hydrogen peroxide; HEt, dihydroethidium; LC3, microtubule-associated protein light chain 3; LDH, lactate dehydrogenase; $\mathrm{mtH}_{2} \mathrm{O}_{2}$, mitochondrial hydrogen peroxide; MPTP, mitochondrial permeability transition pore; $\mathrm{O}_{2}^{-}$, superoxide anion; PARP, poly (ADP-ribose) polymerase; ROS, reactive oxygen species; RV, resveratrol; TBI, traumatic brain injury Received 13.11.13; revised 11.2.14; accepted 24.2.14; Edited by A Verkhratsky
} 
The functions of several metabolic, signaling, and structural proteins are regulated by GSK- $3 \beta,{ }^{12,13}$ indicating that GSK-3 $\beta$ has a central role in determining cell survival and apoptosis. GSK-3 $\beta$ is also involved in psychiatric and neurodegenerative diseases such as bipolar disorder, schizophrenia, and Alzheimer's disease. ${ }^{12-16}$ Overexpression of GSK-3 $\beta$ can induce apoptosis in neuron cells, ${ }^{17}$ and GSK-3 $\beta$ can be activated by reactive oxygen species (ROS). ${ }^{18}$ We previously demonstrated that cadmium induces autophagic cell death through the ROS/GSK-3 $\beta$ signaling pathway. ${ }^{19}$ However, whether GSK-3 $\beta$ participates in TBI-induced cell death remains unclear.

Resveratrol (RV) (3,5,4'-trihydroxystilbene) is a polyphenol compound enriched in grape skin, red wine, and nuts, and acts as a powerful antioxidant. ${ }^{20} \mathrm{RV}$ exerts neuroprotective effects in neurodegenerative diseases such as Alzheimer's disease, Huntington's disease, and Parkinson's disease, and can protect the brain against damage induced by toxins and disease. ${ }^{21}$ Administration of $\mathrm{RV}$ in gerbils with cerebral ischemic injury was reported to reduce neuronal cell death and glial cell activation. ${ }^{22}$ However, the protective effect and mechanisms of RV after TBI require further examination.

The results of this study showed that the levels of microtubule-associated protein light chain 3 (LC3)-II and phospho-tyr216-GSK-3 $\beta$ increased in rat brains with TBI. To mimic the TBI model in vitro, we treated normal astrocytes, CTX TNA2 cells, with glutamate, which induced apoptotic and autophagic cell death by activating GSK-3 $\beta$. The in vitro and in vivo TBI models revealed that $\mathrm{RV}$ treatment increased cell viability and reduced apoptosis and autophagy by suppressing ROS generation and GSK-3 $\beta$ activation. ROS activated GSK-3 $\beta$ and caused mitochondrial dysfunction including the opening of mitochondrial permeability transition pore (MPTP) and mitochondrial depolarization, which resulted in cytotoxicity of astrocytes. In summary, our results suggested that the administration of RV can serve as a strategy for treating patients with TBI.

\section{Results}

Autophagy is induced after TBI in rats. To determine whether autophagy was induced after TBI, the rats were subjected to TBI, and the procession of the LC3-II protein, a hallmark of autophagy, was detected using immunoblotting. Compared with the level in a sham group, the LC3-II protein level in the damaged brain region increased from 0.5 to $4 \mathrm{~h}$ after TBI and subsequently decreased $24 \mathrm{~h}$ after TBI (Figures $1 \mathrm{a}$ and $\mathrm{b}$ ). Furthermore, the level of phospho-Ser9-GSK-3 $\beta$ decreased from 0.5 to $24 \mathrm{~h}$ after TBI (Figure 1c), whereas the level of phospho-Tyr216-GSK-3 $\beta$ increased after $0.5 \mathrm{~h}$ (Figure 1d). These results indicated that TBI can induce autophagy and GSK-3 $\beta$ activation.

Glutamate treatment induces cell death in CTX TNA2 astrocytes. An in vitro TBI model was used to further analyze the mechanism of TBI-induced cell death. On the basis of the glutamate concentrations used by Karmarkar et al., ${ }^{23}$ CTX TNA2 cells were treated with $0-10 \mathrm{mM}$ glutamate for $48 \mathrm{~h}$ and then observed using a reverse-phase microscope. Glutamate treatment reduced the cell numbers and caused cell shrinkage (Figure 2a). Moreover, the results of MTT assay and lactate dehydrogenase (LDH) release assay revealed that cell viability decreased (Figure $2 b$ ) and cytotoxicity increased (Figure 2c), respectively, in a dosedependent manner. The $\mathrm{IC}_{50}$ of glutamate was calculated to be $8.2 \mathrm{mM}$, based on the data of the MTT assay. Therefore,

a
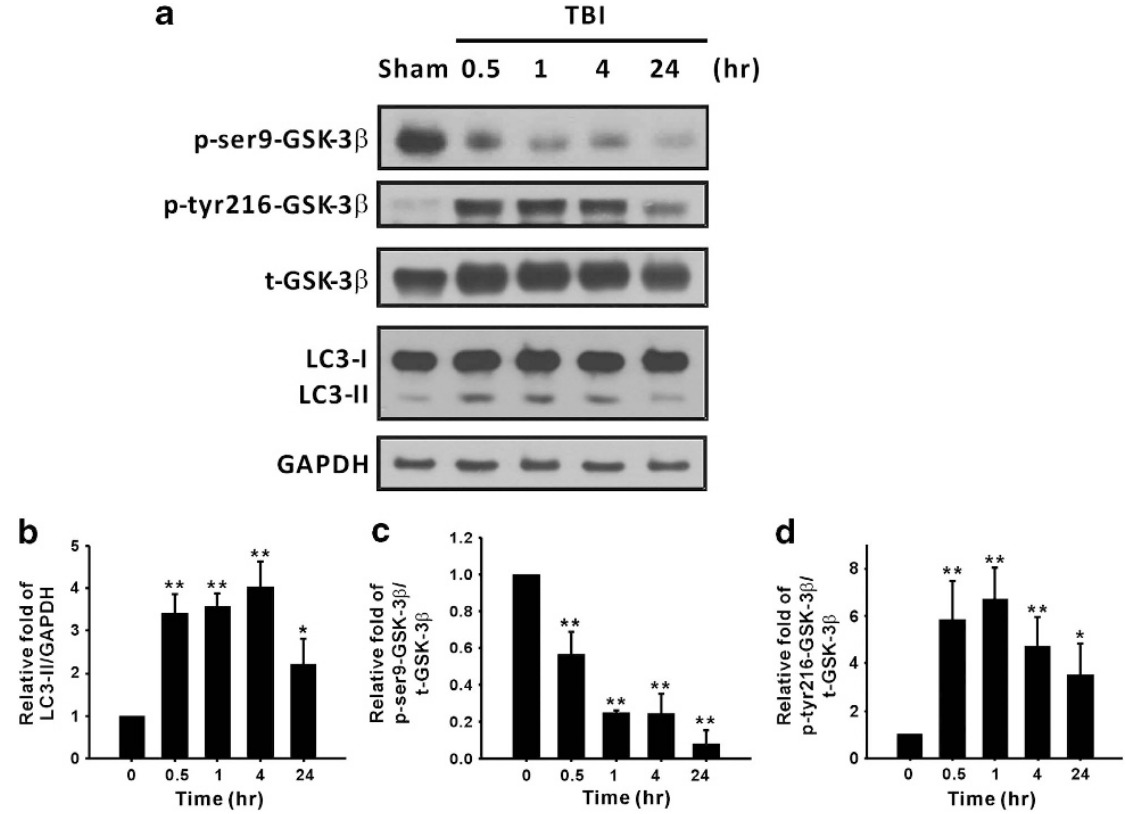

Figure 1 TBI induces autophagy and the activation of GSK-3 $\beta$ in rat brains. (a) Immunoblotting analysis of GSK-3 $\beta$ as a function of time after TBI. Rat brains were removed after a specified time. Protein was extracted and analyzed using immunoblotting with anti-LC3, anti-p-ser9-GSK-3 $\beta$, anti-p- tyr216-GSK-3 $\beta$, anti-t-GSK-3 $\beta$, and antiGAPDH antibodies. GAPDH and t-GSK-3 $\beta$ were used as internal controls to normalize the amount of proteins. (b-d) The statistical results are presented as mean \pm S.E.M. ( $n=3 /$ group). ${ }^{*} P<0.05,{ }^{* *} P<0.01$ versus the respective control, one-way ANOVA 


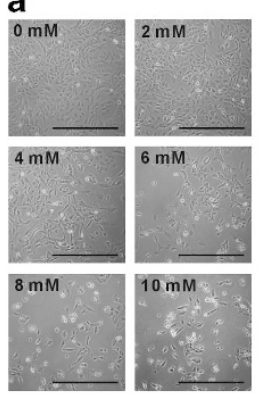

b

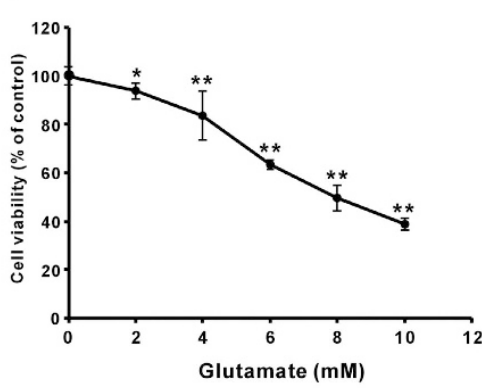

C

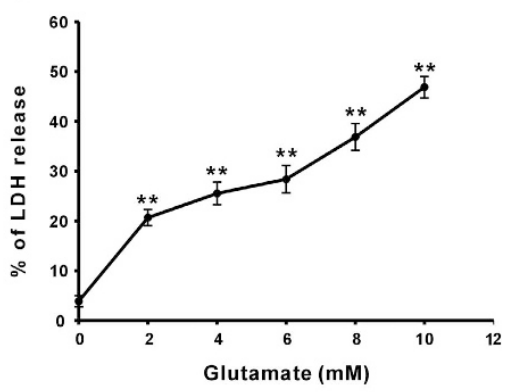

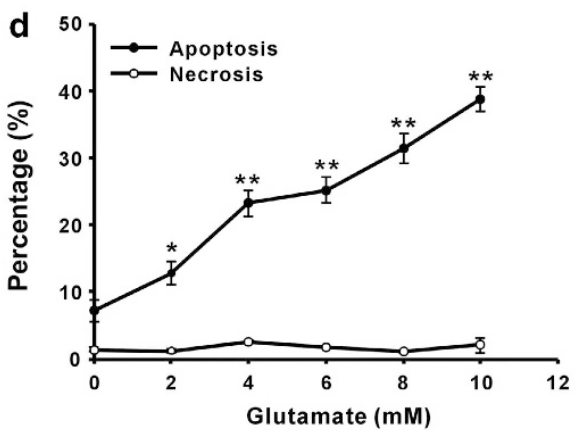

e
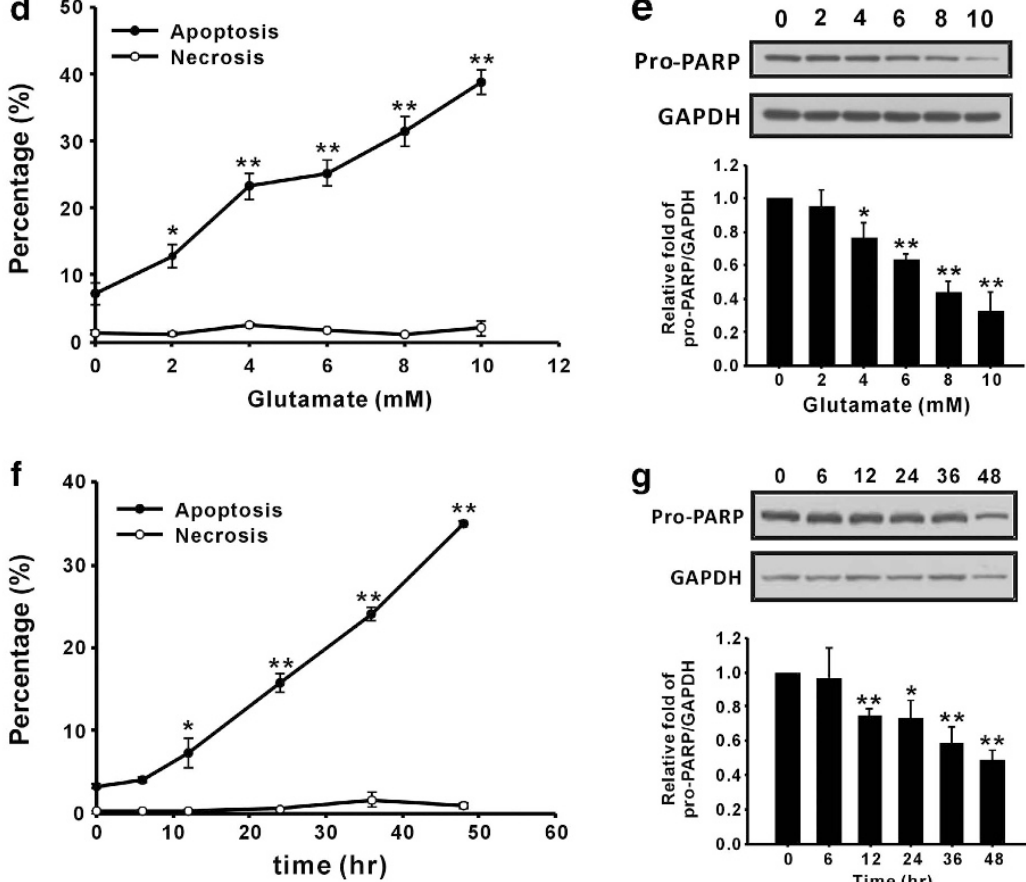
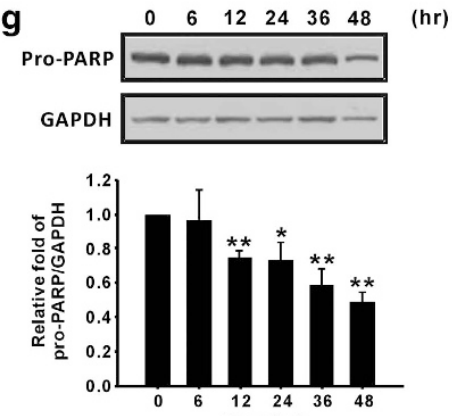

Figure 2 Glutamate reduces cell viability and induces apoptosis in the dose- and time-dependent manners. CTX TNA2 cells were treated with $0-10 \mathrm{mM} \mathrm{glutamate}$ for $48 \mathrm{~h}$ (a-e) or $8 \mathrm{mM}$ glutamate for $0-48 \mathrm{~h}$ ( $\mathrm{f}$ and $\mathbf{g}$ ) in time course experiments. (a) The morphology of cells was examined and cells were photographed using a reverse-phase microscope. Scale bar, $100 \mu \mathrm{m}$. Cell viability and cytotoxicity were analyzed using the MTT assay (b) and the LDH release assay (c), respectively. (d and f) The modes of cell death were analyzed using flow cytometry with annexin V/PI staining. (e and $\mathbf{g}$ ) Cell lysates ( $30 \mu \mathrm{g} /$ lane) were analyzed using immunoblotting with anti-PARP and anti-GAPDH

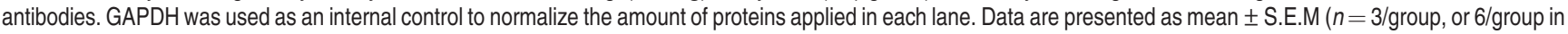
the MTT assay). ${ }^{*} P<0.05,{ }^{*} P<0.01$ versus respective controls, one-way ANOVA

we mainly used a dose of $8 \mathrm{mM}$ glutamate in this study. When cells were treated with $8 \mathrm{mM}$ glutamate for $0-48 \mathrm{~h}$, cell numbers and viability decreased over time (Supplementary Figures $1 \mathrm{a}$ and b), whereas the ratio of $\mathrm{LDH}$ release increased (Supplementary Figure 1c), suggesting that glutamate induced cytotoxicity in a time-dependent manner. We subsequently investigated the mode of cell death by using flow cytometry with annexin V/propidium iodide (PI) staining. The percentage of cells undergoing apoptosis (but not necrosis) increased after treatment with $0-10 \mathrm{mM}$ glutamate (Figure 2d), and the pro-form of poly (ADP-ribose) polymerase (PARP) protein decreased (Figure 2e), as detected by immunoblotting. The time course experiments also indicated that glutamate treatment induces apoptosis (Figures $2 \mathrm{f}$ and $\mathrm{g}$ ). The data indicated that glutamate induces cytotoxicity of CTX TNA2 astrocyte cells by triggering apoptosis in the dose- and time-dependent manners.
Glutamate-induced autophagy results in cell death. Autophagy is defined as type II programmed cell death. Therefore, to investigate whether glutamate can induce autophagy, the amount of acidic vesicular organelles (AVOs) was quantified using acridine orange staining on a flow cytometer. As shown in Figures $3 a$ and $b$, the percentage of cells undergoing autophagy increased in the dose- and timedependent manners. In addition, the LC3-II protein increased with the glutamate dosage and time course (Figure $3 \mathrm{c}$ ). To further verify that LC3-II accumulation was caused by autophagy induction, autophagic flux was monitored using an LC3 turnover assay. ${ }^{24,25}$ The presence of the lysosomal inhibitor bafilomycin A1 (BAF) resulted in LC3-II accumulation. As shown in Figure $3 \mathrm{~d}$, treatment with $8 \mathrm{mM}$ glutamate and $2 \mathrm{nM}$ BAF for $24 \mathrm{~h}$ led to greater LC3-II accumulation than did glutamate treatment alone. The autophagic substrate protein p62/SQSTM1 is also used as a marker of 

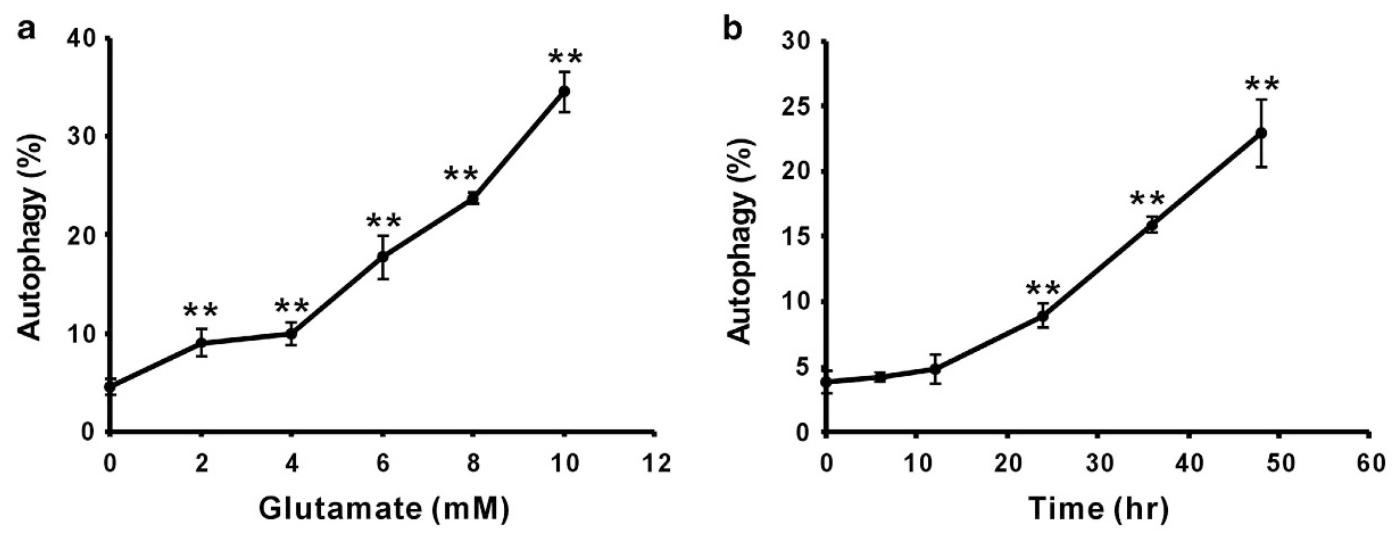

c
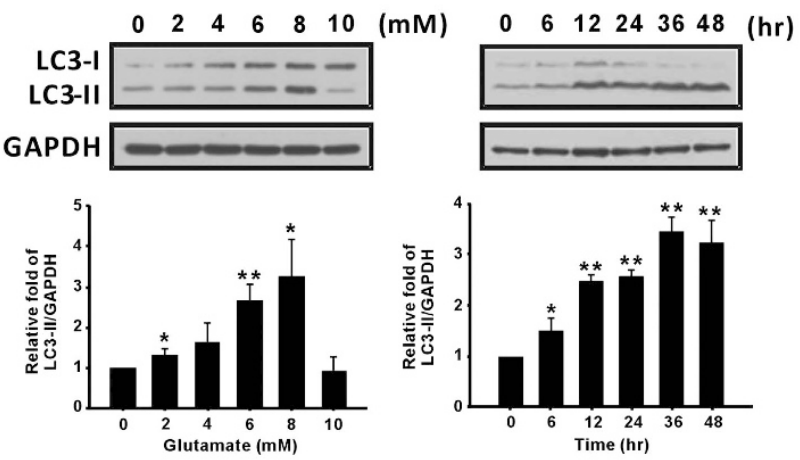

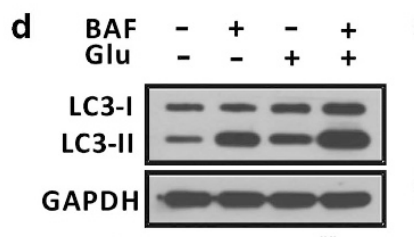

e

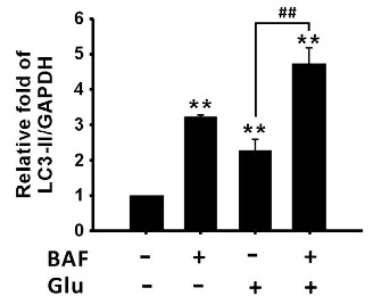

Figure 3 Glutamate induces autophagy in astrocytes in the dose- and time-dependent manners. ( $\mathbf{a}$ and $\mathbf{b}$ ) Cells were treated as described in the legend of Figures $2 a$ and $b$. The percentages of AVOs were analyzed using flow cytometry with acridine orange staining. (c) CTX TNA2 cell lysates ( $30 \mu \mathrm{g} /$ lane) were analyzed using immunoblotting with anti-LC3 and anti-GAPDH antibodies. (d) CTX TNA2 cells were treated with $2 \mathrm{nM} \mathrm{BAF}$ and $8 \mathrm{mM}$ glutamate for $24 \mathrm{~h}$, and cell lysates were analyzed using immunoblotting. (e) The p62 protein level was analyzed using immunoblotting. GAPDH was used as an internal control to normalize the amount of proteins applied in each lane. Glu, glutamate. Data are presented as mean \pm S.E.M. ( $n=3$ /group). ${ }^{*} P<0.05,{ }^{* *} P<0.01$ versus the respective control; ${ }^{\# \#} P<0.01$ versus the glutamate group, one-way ANOVA

autophagic flux. ${ }^{26}$ As shown in Figure $3 e$, the level of p62 decreased from 6 to $48 \mathrm{~h}$ after glutamate treatment, suggesting that glutamate treatment causes autophagy induction in CTX TNA2 cells. Moreover, pharmacological inhibition of autophagy by 3-methyladenine (3-MA) (Figure $4 \mathrm{a}$ ) resulted in a reduction in apoptosis (Figure $4 \mathrm{~b}$ ) and an increase in cell numbers (Figure 4c) and cell viability (Figure $4 \mathrm{~d}$ ). The $\mathrm{LDH}$ release assay also indicated that cytotoxicity was diminished when cells were treated with both glutamate and 3-MA (Figure 4e), indicating that glutamateinduced autophagy leads to cell death. These results suggested that glutamate-induced autophagy caused CTX TNA2 cell death and may be related to apoptosis.

Glutamate treatment activates GSK-3 $\beta$ to induce cell death. The involvement of GSK-3 $\beta$ in glutamate-induced cytotoxicity was examined. As shown in Figure 5a, after $8 \mathrm{mM}$ glutamate treatment, the levels of phosphotyr216-GSK-3 $\beta$ and phospho-ser9-GSK-3 $\beta$ increased and decreased over time, respectively. The GSK-3 $\beta$ inhibitor, SB216763, was used to examine whether GSK-3 $\beta$ has a role in glutamate-induced cytotoxicity. When cells were exposed to both glutamate and SB216763, the cell numbers increased (Figure 5b) through suppressing glutamate-induced autophagy and apoptosis (Figure 5c), and thus cell viability increased (Figure 5d), leading to a reduced cytotoxicity (Figure 5e). The data from immunoblotting verified these results (Supplementary Figure 2 ). These results indicated that glutamate induces autophagy and apoptosis through GSK-3 $\beta$ activation in astrocytes. To further investigate the function of GSK-3 $\beta$, CTX TNA2 cells were transfected with small-interfering RNAs (siRNAs) to knockdown GSK-3 $\beta$ expression (Supplementary Figure 3); using the siRNAs at $100 \mathrm{nM}$ effectively knocked down protein expression. The siRNA of GSK-3 $\beta$ reduced the percentages of cells undergoing autophagy and apoptosis (Figure 5f) and increased cell survival (Figure $5 \mathrm{~g}$ ). Conversely, overexpression of GSK-3 $\beta$ by transfection of the GSK-3 $\beta$-S9A dominant active plasmid further increased glutamate-induced autophagy and apoptosis (Figure $5 \mathrm{~h}$ ) and reduced cell viability (Figure 5i). These results revealed that GSK-3 $\beta$ activation participates in glutamate-induced autophagic and apoptotic cell death.

RV protects astrocytes against glutamate-induced cytotoxicity by inhibiting ROS accumulation. To determine whether RV can protect astrocyte cells from glutamate excitotoxicity, 1-5 $\mu \mathrm{M}$ RV was combined with glutamate for 

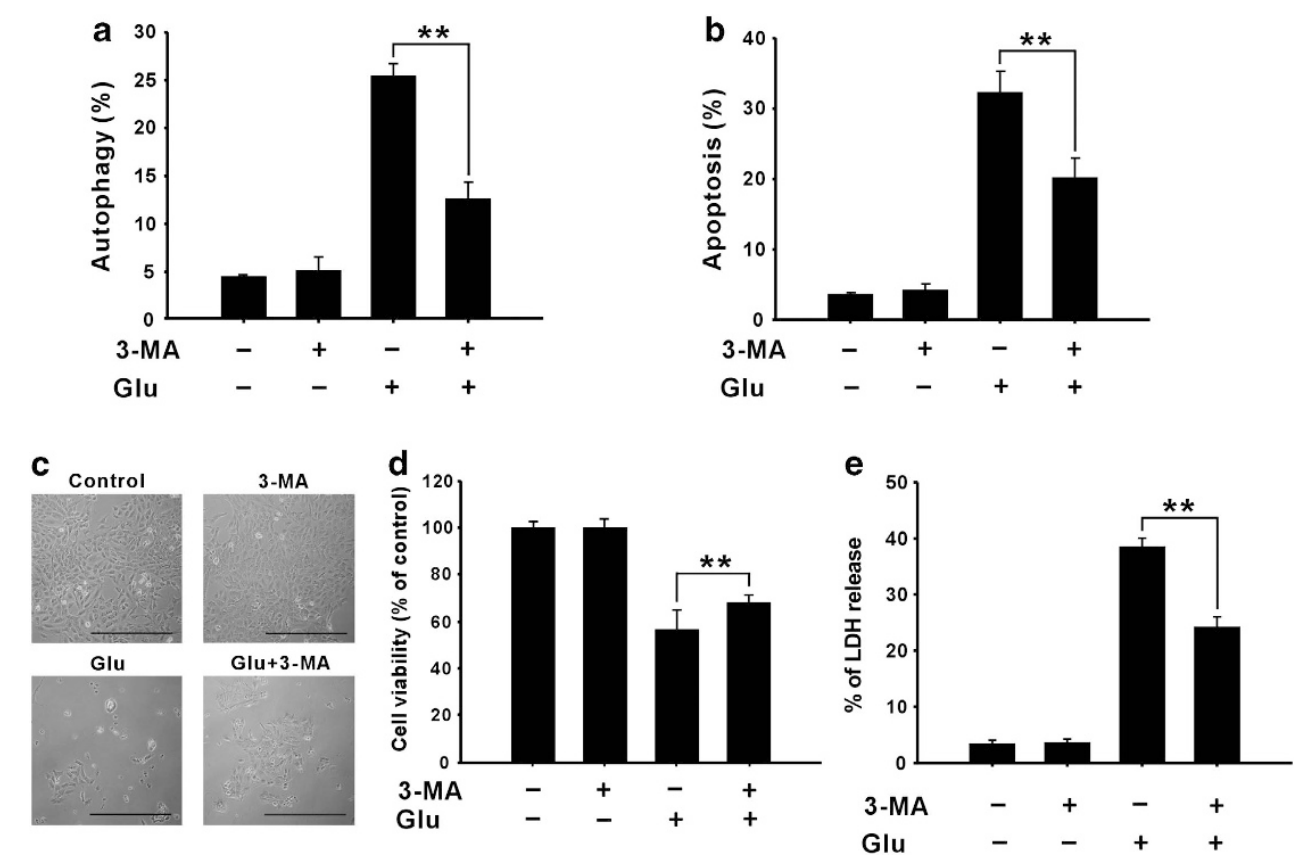

Figure 4 Glutamate-induced autophagy leads to cell death. CTX TNA2 cells were pretreated with $1 \mathrm{mM} \mathrm{3-MA}$ for $1 \mathrm{~h}$, and $8 \mathrm{mM}$ glutamate was subsequently added for another $48 \mathrm{~h}$. The percentages of cells undergoing autophagy (a) and apoptosis (b) were measured as described in Materials and Methods. (c) The morphology of cells was examined and the cells were photographed using a reverse-phase microscope. Scale bar, $100 \mu \mathrm{m}$. Cell viability and cytotoxicity were analyzed using the MTT assay (d) and the LDH release assay (e), respectively. Glu, glutamate. Data are presented as mean \pm S.E.M. ( $n=3 /$ group, or $6 /$ group in the MTT assay). ${ }^{* *} P<0.01$, Student's t-test

$48 \mathrm{~h}$ and the effects on cell morphology and viability were examined. RV treatment increased cell numbers (Figure 6a) and cell viability (Figure $6 \mathrm{~b}$ ) and, in parallel, lowered the percentage of LDH release (Figure $6 \mathrm{c}$ ), as a result of the suppression of glutamate-induced autophagy and apoptosis (Figure 6d). Furthermore, LC3 processing and PARP cleavage were decreased following treatment with $5 \mu \mathrm{M} R \mathrm{RV}$ in vitro (Figure $6 \mathrm{e}$ ) and $100 \mathrm{mg} / \mathrm{kg}$ of $\mathrm{RV}$ in vivo (Figure 6f). These results indicated that $\mathrm{RV}$ can protect astrocytes against glutamate-induced cell death by inhibiting autophagy and apoptosis.

Because ROS function upstream of GSK-3 $\beta$, we examined the relationship between ROS and GSK-3 $\beta$ in glutamateinduced cytotoxicity. As shown in Figure 7, after cells were exposed to $8 \mathrm{mM}$ glutamate, the levels of ROS, including superoxide anion $\left(\mathrm{O}_{2}^{-}\right)$, hydrogen peroxide $\left(\mathrm{H}_{2} \mathrm{O}_{2}\right)$, and mitochondrial hydrogen peroxide $\left(\mathrm{mtH}_{2} \mathrm{O}_{2}\right)$, increased significantly within $6 \mathrm{~h}$ (Figures $7 \mathrm{a}-\mathrm{c}$ ) and were then sustained up to $48 \mathrm{~h}$ in the case of $\mathrm{O}_{2}^{--}$and $\mathrm{H}_{2} \mathrm{O}_{2}$ and up to $24 \mathrm{~h}$ in the case of $\mathrm{mtH}_{2} \mathrm{O}_{2}$. The addition of $5 \mu \mathrm{M} \mathrm{RV}$ for $24 \mathrm{~h}$ suppressed the glutamate-triggered ROS bursts (Figure 7d). Moreover, $\mathrm{RV}$ treatment reduced the phosphorylation of GSK-3 $\beta$ at Typ-216 and increased the phosphorylation of GSK-3 $\beta$ at Ser9 in vitro (Figure 7e) and in vivo (Figure 7f). These results suggested that the generation of ROS following glutamate treatment can induce GSK-3 $\beta$ activation. In parallel experiments, we used another antioxidant, vitamin $\mathrm{C}$, to confirm the effect of RV. Adding $5-50 \mu \mathrm{M}$ vitamin $\mathrm{C}$ with glutamate increased cell viability (Supplementary Figure 4a) and reduced autophagy and apoptosis (Supplementary Figures $4 \mathrm{~b}$ and $\mathrm{c}$ ) by suppressing ROS generation (Supplementary Figure 4d). These results suggested that antioxidants such as $R V$ and vitamin $C$ reduce cell death by inhibiting glutamate-induced ROS generation and GSK-3 $\beta$ activation in normal astrocytes.

\section{Glutamate induces mitochondrial damage-mediated cell} death, which is reduced by RV. To investigate the role of GSK-3 $\beta$ in glutamate-induced mitochondrial damage, we analyzed the characteristics of mitochondrial damage. As shown in Figures $8 \mathrm{a}$ and b, MPTP opening and mitochondrial depolarization were observed from $24 \mathrm{~h}$ after glutamate treatment and were sustained up to $48 \mathrm{~h}$, and these effects were reversed by an MPTP inhibitor, cyclosporine A (CsA) (Figures 8c and d), and RV and SB216763 (Figures 8e and f), respectively. Furthermore, vitamin $C$ suppressed the activation of GSK-3 $\beta$ (Supplementary Figure 5a) and mitochondrial damage (Supplementary Figures $5 \mathrm{~b}$ and $\mathrm{c}$ ). These results suggested that glutamate causes mitochondrial damage through the ROS/GSK-3 $\beta$ pathway. To determine the role of mitochondrial damage in glutamateinduced cell death, the morphology and survival of cells were evaluated using light microscopy and MTT assay, respectively. Combined treatment with $\mathrm{CsA}$ and glutamate increased cell numbers (Figure $8 \mathrm{~g}$ ) and cell viability (Figure $8 \mathrm{~h}$ ) relative to glutamate treatment alone, and reduced glutamate-induced autophagy and apoptosis (Figure 8i); consequently, glutamate-induced cytotoxicity was decreased, as shown by the $\mathrm{LDH}$ release assay (Figure 8j). These results demonstrated that ROS/GSK-3 $\beta$ mediated mitochondrial damage participated in glutamateinduced cytotoxicity. 
a
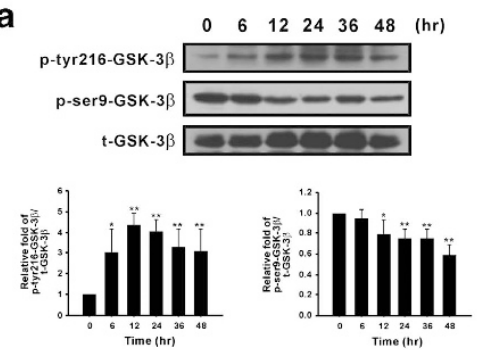

d

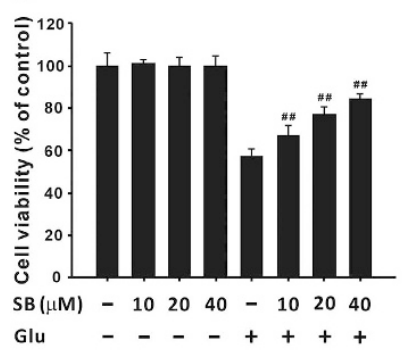

e b
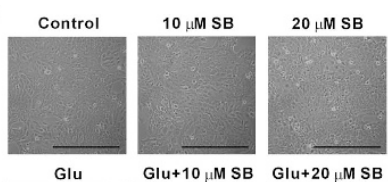

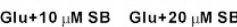
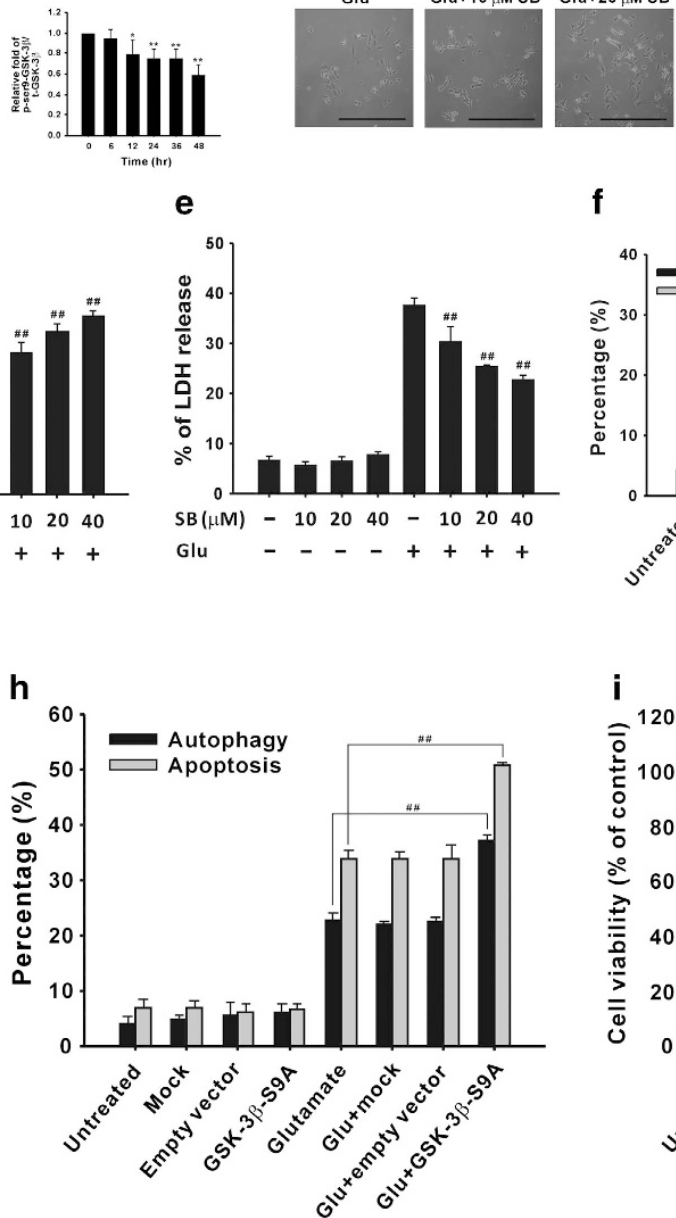

f
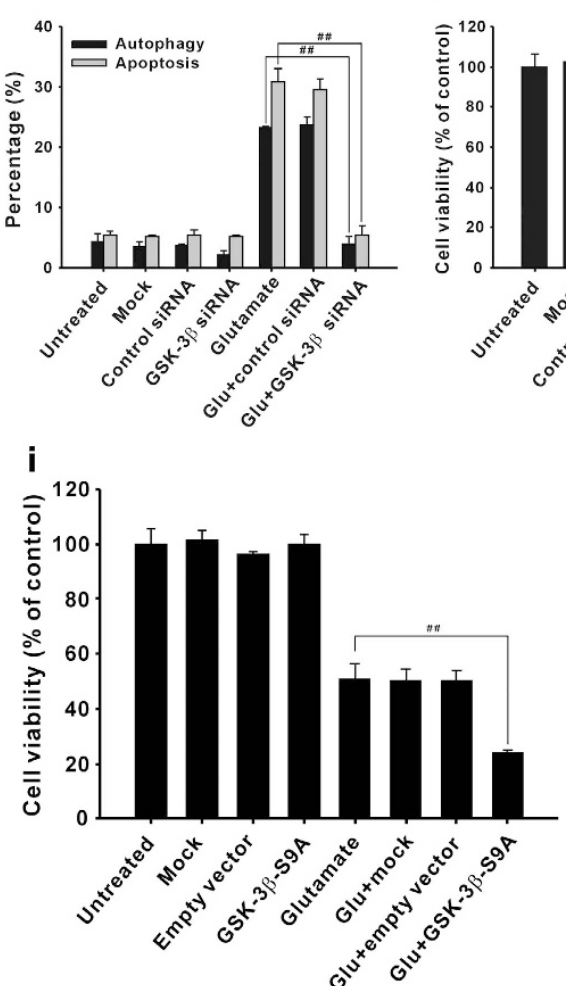

Figure 5 Activation of GSK-3 $\beta$ contributes to glutamate-induced cell death. (a) CTX TNA2 cells were treated with $8 \mathrm{mM}$ glutamate for $0-48 \mathrm{~h}$ and cell lysates ( $30 \mu \mathrm{g} / \mathrm{lane}$ ) were then analyzed using immunoblotting with anti-p-tyr216-GSK-3 $\beta$, anti-p-Serg-GSK-3 $\beta$, and anti-t-GSK-3 $\beta$ antibodies. T-GSK-3 $\beta$ was used as an internal control to normalize the amount of proteins. (b-e) Cells were pretreated with 10-40 $\mathrm{M}$ SB216763 for $1 \mathrm{~h}$ and then treated with glutamate for $48 \mathrm{~h}$. (b) The morphology of cells was examined and the cells were photographed using a reverse-phase microscope. Scale bar, $100 \mu \mathrm{m}$. (c) The percentages of cells undergoing autophagy and apoptosis were measured as described in Materials and Methods. Cell viability and cytotoxicity were analyzed using the MTT assay (d) and the LDH release assay (e), respectively. (f and $\mathbf{g}$ ) Cells were transfected with $100 \mathrm{nM}$ control siRNA or GSK-3 $\beta$ siRNA for $48 \mathrm{~h}$ and then treated with $8 \mathrm{mM}$ glutamate for another $48 \mathrm{~h}$ to determine the percentages of cells undergoing autophagy and apoptosis (f) and the cell viability (g). ( $\mathrm{h}$ and i) Cells were transfected with $2 \mu \mathrm{g} \mathrm{pcDNA3}$ or GSK-3 $\beta$-S9A dominant active plasmid for $48 \mathrm{~h}$ and then treated with $8 \mathrm{mM}$ glutamate for another $48 \mathrm{~h}$ to determine autophagy and apoptosis (h) and the cell viability (i). SB, SB216763; Glu, glutamate. Data are presented as mean \pm S.E.M. ( $n=3 /$ group; 6/group in the MTT assay). ${ }^{*} P<0.05,{ }^{* *} P<0.01$ versus respective controls. ${ }^{\#} P<0.05,{ }^{\#} P<0.01$ versus each respective glutamate group, one-way ANOVA

\section{Discussion}

The excitatory amino acid, glutamate, induces secondary injuries and leads to the excitotoxicity in neuronal and glial cells. ${ }^{9}$ In this study, normal astrocytes CTX TNA2 cells were administrated with glutamate to mimic TBI in vitro. Our results showed that glutamate can induce excitotoxicity in astrocytes. Glutamate-induced neuronal apoptosis may be dependent on calcium overload, ER stress induction, and ROS generation. ${ }^{7,11,27}$ Except for apoptosis, recent studies have indicated that autophagy is linked to TBI. ${ }^{28}$ Moreover, autophagic cell death was induced in glutamate-mediated neurotoxicity and in experimental spinal cord injury $(\mathrm{SCl}) .{ }^{29-31}$ Here, we have shown for the first time that TBI-induced cytotoxicity in astrocytes occurs through autophagic and apoptotic cell death in vivo and in vitro. Although apoptosis and autophagy are classed as type I and type II programmed cell death, respectively, numerous studies have addressed the relationship between autophagy and apoptosis. For example, autophagy was reported to be involved in TBI-induced apoptosis. ${ }^{32}$ Our results showed that inhibition of autophagy by 3-MA reduced glutamate-induced apoptosis (Figure 4), suggesting that autophagy is required for inducing apoptosis during TBI. However, the relationship between glutamate-induced autophagy and apoptosis requires further investigation. 
a

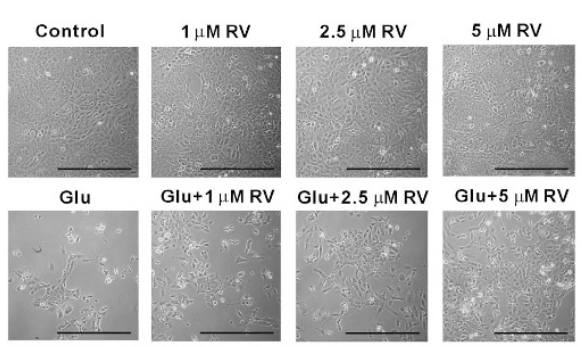

d

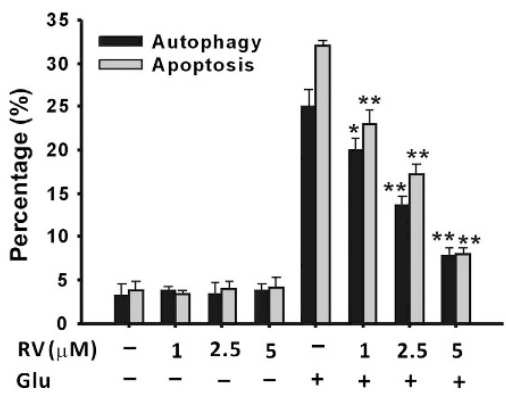

b

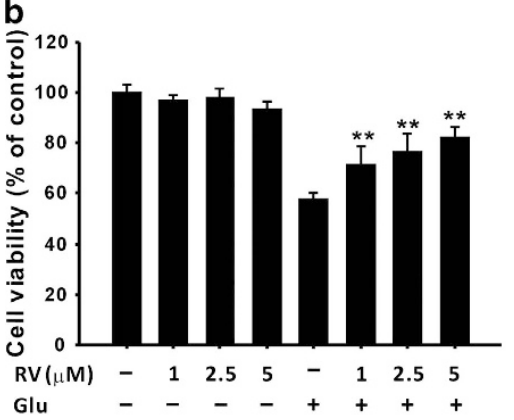

e

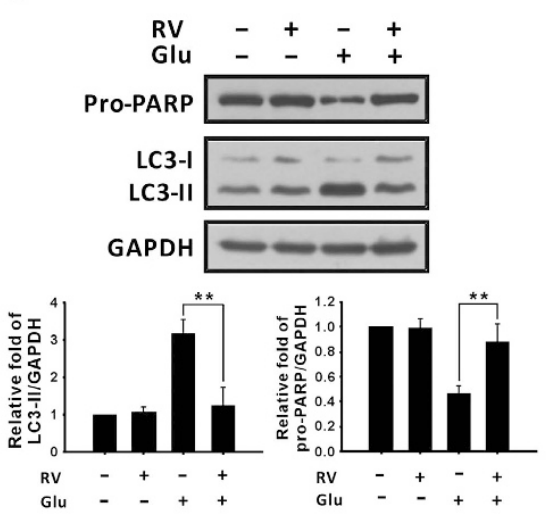

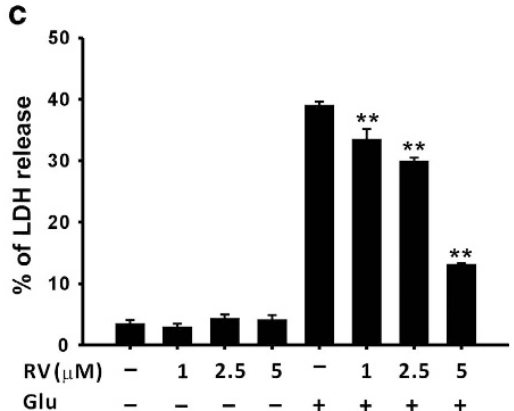

f

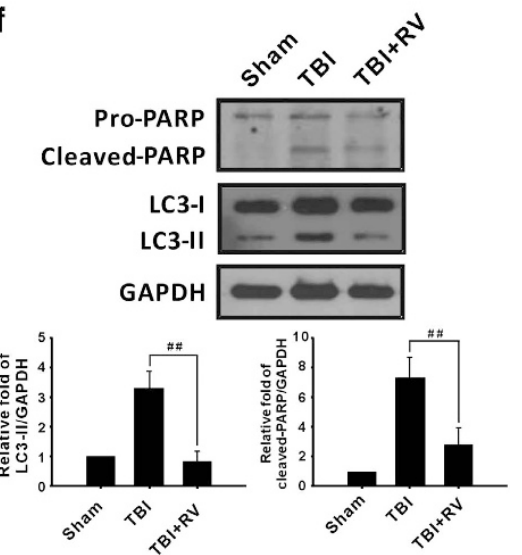

Figure 6 RV reduces glutamate-induced cytotoxicity. (a-d) CTX TNA2 cells were treated with or without 1-5 $\mu \mathrm{M} \mathrm{RV}$ for $1 \mathrm{~h}$ and then treated with $8 \mathrm{mM}$ glutamate for another $48 \mathrm{~h}$. (a) The morphology of cells was examined and the cells were photographed using a reverse-phase microscope. Scale bar, $100 \mu \mathrm{m}$. Cell viability and cytotoxicity were analyzed using the MTT assay (b) and the LDH release assay (c), respectively. (d) Autophagy and apoptosis were evaluated as described in Materials and Methods. (e and f) U87 MG cells were treated with $5 \mu \mathrm{M} \mathrm{RV}$ and $8 \mathrm{mM}$ glutamate for $48 \mathrm{~h}(\mathbf{e})$. RV (100 mg/kg) was administered for $6 \mathrm{~h}$ to rats with TBI (f). Proteins extracted were then analyzed using immunoblotting with anti-PARP, anti-LC3, and anti-GAPDH antibodies. GAPDH was used as an internal control to normalize the amount of proteins applied in each lane. Glu, glutamate. Data are presented as mean \pm S.E.M ( $n=3$ /group; $6 /$ group in the MTT assay). ${ }^{*} P<0.05,{ }^{*} P<0.01$ versus each respective glutamate group. ${ }^{\#} P<0.01$ versus the TBI group, one-way ANOVA

The reduction of cell death during $\mathrm{TBI}$, especially in secondary brain damage, is a crucial clinical issue. ROS are generated after injury, and leads to neuronal cell death. ${ }^{9}$ Antioxidants such as edaravone and schizandrin can protect neurons against glutamate-induced necrosis and apoptosis, respectively. ${ }^{33,34}$ Similar to these studies, we demonstrated that $\mathrm{ROS}$, including intracellular $\mathrm{O}_{2}^{--}, \mathrm{H}_{2} \mathrm{O}_{2}$, and $\mathrm{mtH}_{2} \mathrm{O}_{2}$, were generated after glutamate treatment. Addition of RV and vitamin $C$ suppressed the production of these ROS and thereby reduced cell death (Figures 6 and 7). Previous studies have also shown that $\mathrm{RV}$ can reduce the area of tissue lesions in rats with $\mathrm{TBI}$ and promote neuronal function in rats after $\mathrm{SCl}$ because of the anti-oxidative effect. Therefore, antioxidants such as RV have a protective role after TBI. ${ }^{35,36}$

In this study, experiments using in vivo and in vitro TBI models showed that RV diminishes both autophagic and apoptotic cell death. The study of Armour et al. ${ }^{37}$ indicated that nutrient starvation- and rapamycin-induced autophagy in $\mathrm{NIH} / 3 \mathrm{~T} 3$ cells or HEK293 cells can be attenuated by RV treatment. Another study demonstrated that combination of rapamycin and RV blocks rapamycin-induced autophagy but promotes apoptosis in TSC2-deficient cells. ${ }^{38}$ By contrast, RV can induce protective autophagy to counter the prion protein peptides-induced neurotoxicity. ${ }^{39}$ Moreover, RV was reported to protect $\mathrm{H} 9 \mathrm{c} 2$ cells derived from embryonic rat hearts against $\mathrm{H}_{2} \mathrm{O}_{2}$-induced apoptosis, ${ }^{40}$ and attenuate vascular endothelial inflammation by inducing autophagy. ${ }^{41}$ Therefore, the effect of RV on autophagy might depend on the environment or the stimuli and on the cell type.

Studies conducted using numerous models have indicated that GSK-3 $\beta$ activation has a crucial role in neuronal apoptosis and neurodegenerative diseases. ${ }^{42,43}$ In this study, we demonstrated that glutamate-induced ROS bursts activate GSK-3 $\beta$, which triggers autophagy and apoptosis in normal astrocytes. GSK- $3 \beta$ may induce apoptosis through mitochondrial dysfunction. For example, treatment of neuron cells with 1-methyl-4-phenylpyridinium iodide $\left(\mathrm{MPP}^{+}\right)$induces GSK$3 \beta$-mediated mitochondrial depolarization and subsequent caspase 9-dependent cell death. ${ }^{44}$ Conversely, inhibition of GSK-3 $\beta$ by SB216763 or hydrogen sulfide may protect cardiomyocytes against apoptosis through inhibiting the opening of MPTP. ${ }^{45,46}$ Our results showed that SB216763 treatment increases the viability of glutamate-treated astrocytes by reducing apoptosis and autophagy, which indicates that GSK-3 $\beta$ activation induces not only apoptosis, but also autophagy. Previously, we demonstrated that cadmium also activated the GSK-3 $\beta$-mediated autophagic cell death pathway. ${ }^{19}$ In lung epithelial cells, autophagy was also suppressed upon inhibition of GSK-3 $\beta$ by interleukin-17A, which promoted the association of BCL2 and BECN1. ${ }^{47}$ However, Parr et al. ${ }^{48}$ 

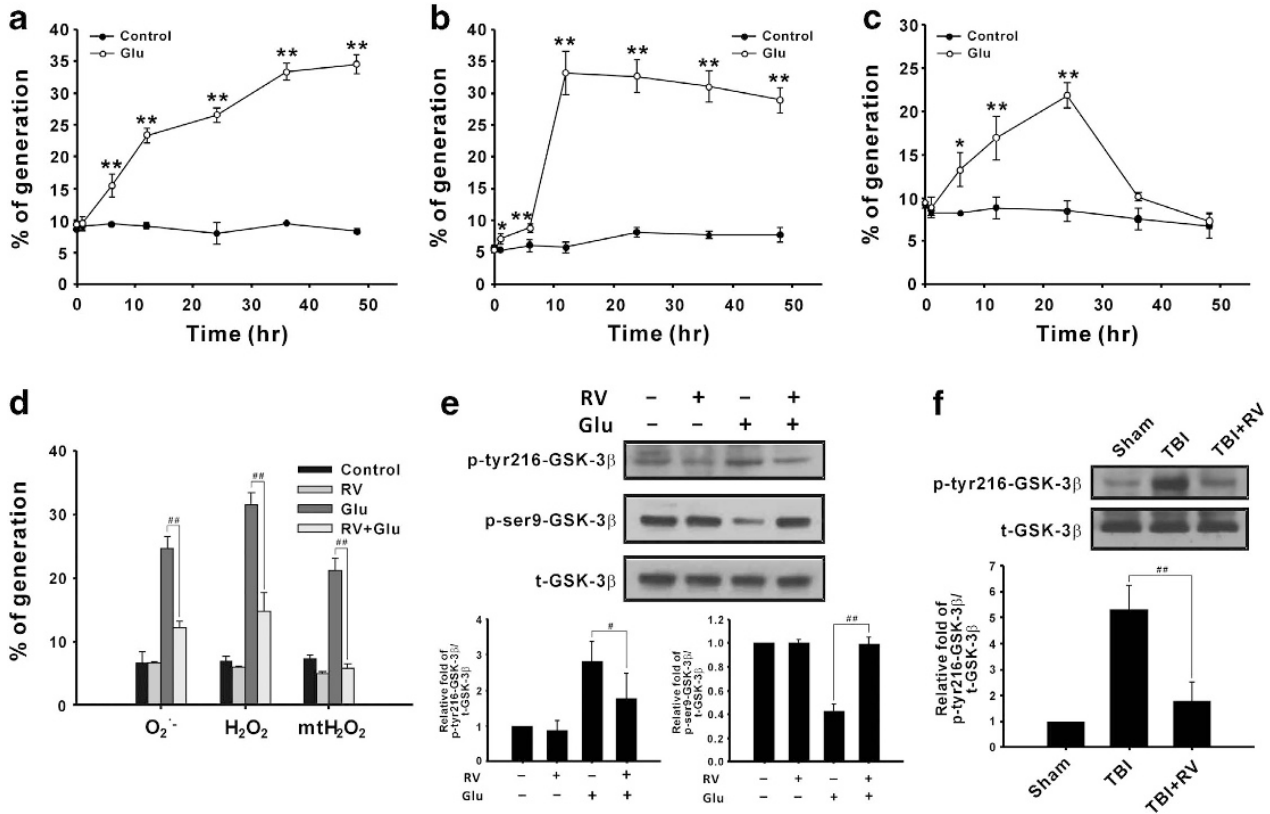

Figure 7 Glutamate increases ROS generation, which induces GSK-3 $\beta$ activation. (a-c) CTX TNA2 cells were treated with 8 mM glutamate for various periods. The levels of $\mathrm{O}_{2}^{--}$, cytosolic $\mathrm{H}_{2} \mathrm{O}_{2}$, and $\mathrm{mtH}_{2} \mathrm{O}_{2}$ were analyzed using a flow cytometer with $\mathrm{HEt}(\mathbf{a})$, DCFH-DA (b), and DHR123 (c) staining, respectively. (d) Cells were pretreated with or without $5 \mu \mathrm{M} \mathrm{RV}$ for $1 \mathrm{~h}$ and then incubated with $8 \mathrm{mM}$ glutamate for $24 \mathrm{~h}$; the ROS levels were subsequently analyzed. (e and f) Proteins extracted from U87 MG cells (e) or rat brain tissues (f) were analyzed using immunoblotting with the indicated antibodies. Glu, glutamate. Data are presented as mean \pm S.E.M. $\left(n=3 /\right.$ group). ${ }^{*} P<0.05,{ }^{* *} P<0.01$ versus each respective control. ${ }^{\#} P<0.05,{ }^{\# \#} P<0.01$ versus each respective glutamate group, one-way ANOVA

showed that inhibition of GSK-3 induces the lysosomal/ autophagy pathway to degrade the amyloid precursor protein. Therefore, how GSK-3 $\beta$ regulates autophagy remains unresolved.

Previous studies have indicated that, depending on the concentration used, RV exerts opposite effects on GSK-3 $\beta$ activation. Using RV at low concentrations $(1-10 \mu \mathrm{M})$ leads to the phosphorylation at Ser9 site to inhibit GSK-3 $\beta$, whereas adding $\mathrm{RV}$ at $20 \mu \mathrm{M}$ activates GSK-3 $\beta$ to regulate angiogenesis in human umbilical vein endothelial cells, ${ }^{49}$ and treatment with $>50 \mu \mathrm{M}$ RV inhibit the phosphorylation of GSK-3 $\beta$ to basal levels in MCF-7 cells. ${ }^{50}$ Shin et al. ${ }^{51}$ showed that RV protects arachidonic acid/iron-treated hepatocytes against oxidative stress-mediated mitochondrial dysfunction and apoptosis through inhibiting GSK-3 $\beta$. In this study, low concentrations of $\mathrm{RV}(1-5 \mu \mathrm{M})$ reduces GSK-3 $\beta$ activation and mitochondrial damage and thereby diminished glutamate-induced cytotoxicity (Figures 6 and 8). RV treatment also provides neuroprotection by inactivating GSK-3 $\beta$ in an Alzheimer's disease transgenic mouse model and in oxygen-glucose deprivation-treated organotypic hippocampal slice cultures. ${ }^{52,53}$ Therefore, inhibition of GSK-3 $\beta$ by RV might reduce glutamate excitotoxicity, which raises the possibility of using RV in clinical therapies developed for patients with TBI.

In conclusion, treating CTX TNA2 astrocytes with glutamate to imitate the brain condition after TBI showed that glutamate induces ROS/GSK-3 $\beta$-dependent mitochondrial damage, including mitochondrial depolarization and MPTP opening, and leads to autophagic and apoptotic cell death in astrocytes. $\mathrm{RV}$, an antioxidant, improved cell survival by inhibiting ROS-mediated GSK-3 $\beta$ activation in vivo and in vitro.
Therefore, we propose that administering RV might serve as a strategy for clinical treatment of patients with TBI.

\section{Materials and Methods}

Reagents and antibodies. DMEM media and supplements were purchased from Hyclone (Logan, UT, USA). CsA and 3-(4,5-dimethyl-2-thiazolyl)-2, 5-dimethyl-2H-tetrazolium bromide (MTT) were purchased from Merck (Darmstadt, Germany). Acridine orange, 3-MA, $\mathrm{CoCl}_{2}, \mathrm{SB} 216763$, and 5,5',6,6',-tetrachloro$1,1^{\prime}, 3,3^{\prime}$-tetraethylbenzimidazolylcarbocyanine iodide (JC-1) were purchased from Sigma (St. Louis, MO, USA), and 2,7-dihydrodichlorofluorescein diacetate (DCFH$\mathrm{DA})$, dihydroethidium (HEt), and dihydrorhodamine 123 (DHR123) were purchased from Molecular Probes (Eugene, OR, USA). A protease inhibitor cocktail was purchased from Roche (Boehringer Mannheim, Germany). Polyvinylidene difluoride (PVDF) membrane was purchased from Millipore (Bedford, MA, USA). Protein Assay Dye Reagent was obtained from Bio-Rad Laboratories (Hercules, CA, USA). The phenol red-free RPMI 1640 medium, penicillin/streptomycin, sodium pyruvate, calcein AM, Hank's balanced salt solution (containing calcium) (HBSS/Ca), and 10-N-nonyl-acridine orange were purchased from Invitrogen (Carlsbad, CA, USA). Annexin V was obtained from Biovision (Mountain View, CA, USA). PI was purchased from Calbiochem (San Diego, CA, USA). Anti-LC3 antibody was purchased from NOVUS (Littleton, CO, USA). Anti-glyceraldehyde 3-phosphate dehydrogenase (GAPDH), p-Ser9-GSK-3 $\beta$, GSK-3 $\beta$, GAPDH, and PARP antibodies were purchased from Cell Signaling Technology (Beverly, MA, USA). Anti-p-tyr279/216- GSK-3 $\beta$ antibody was purchased from Millipore (Billerica, MA, USA). An anti-SQSTM1 antibody was purchased from Santa Cruz Biotechnology (Santa Cruz, CA, USA). The secondary antibodies, including horseradish peroxidase (HRP)-conjugated goat anti-mouse and anti-rabbit IgG, were purchased from Jackson ImmunoResearch (West Pine, PA, USA). The GSK-3 $\beta$-S9A (dominant active) plasmid was purchased from Addgene (Cambridge, MA, USA).

TBI model. Adult male Sprague-Dawley rats were purchased from BioLASCO Taiwan Co. Ltd. (Taipei, Taiwan) and were maintained in a temperature-regulated room $\left(21-23^{\circ} \mathrm{C}\right)$ on a $12 / 12 \mathrm{~h}$ light/dark cycle. All procedures complied with the Guide for the Care and Use of the Laboratory Animals published by the National Institutes of Health and were approved by the University Laboratory Animal Care 
a

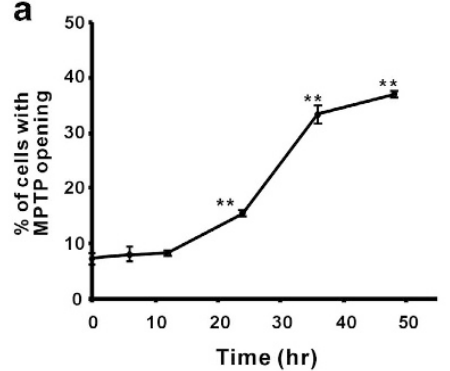

d

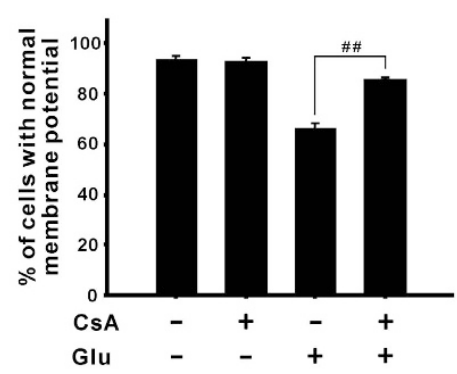

b

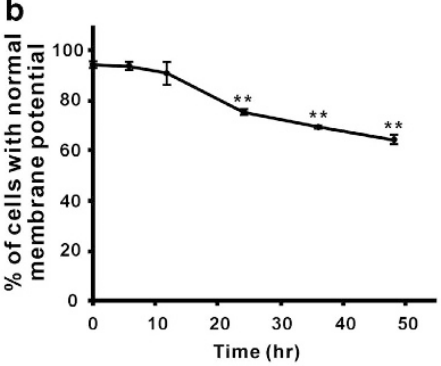

e

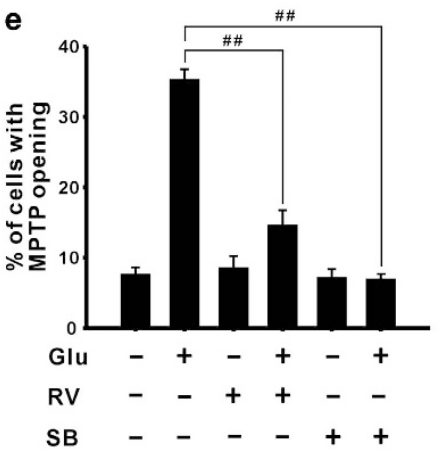

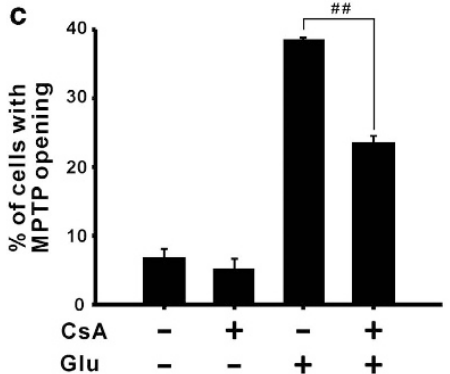

f

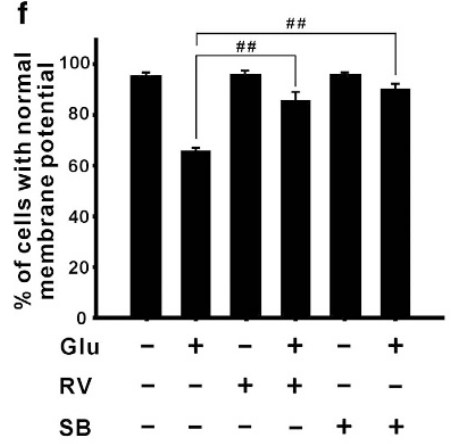

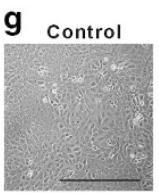

Glu

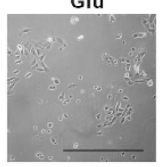

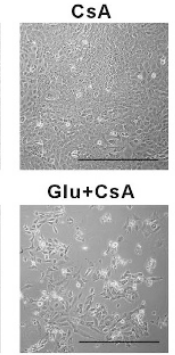
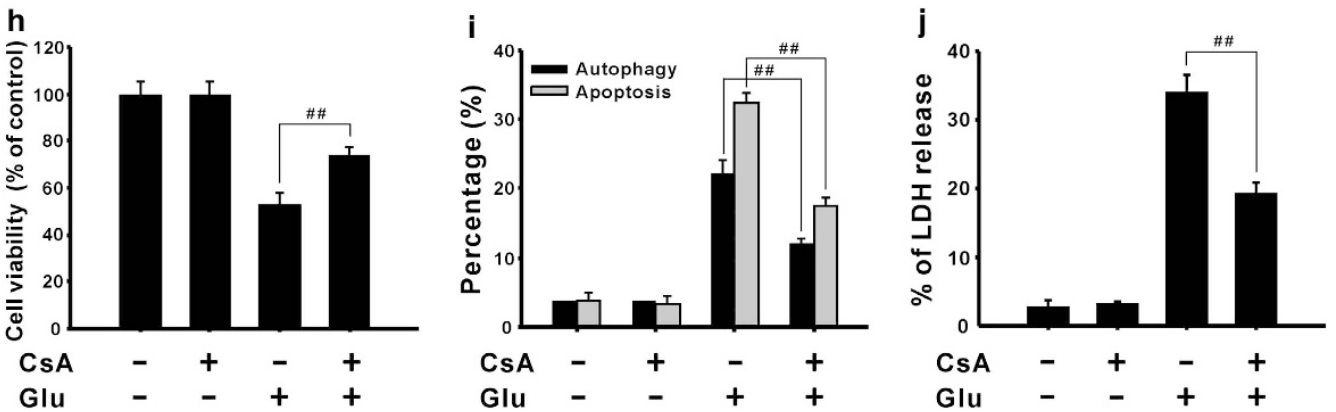

Figure 8 GSK-3 $\beta$ activation induces mitochondrial dysfunction, which results in cell death. (a and $\mathbf{b}$ ) CTX TNA2 cells were treated with $8 \mathrm{mM}$ glutamate for $0-48 \mathrm{~h}$. The opening of MPTP (a) and the mitochondrial membrane potential (b) were measured using flow cytometry with calcein $\mathrm{AM} / \mathrm{CoCl}_{2}$ and $\mathrm{JC}$ - 1 staining, respectively. Cells were pretreated with $1 \mu \mathrm{M} \mathrm{CsA}$ (c and d), $5 \mu \mathrm{M} \mathrm{RV}$, or $40 \mu \mathrm{M} \mathrm{SB} 216763$ (e and f) for $1 \mathrm{~h}$, and then treated with $8 \mathrm{mM}$ glutamate for another $48 \mathrm{~h}$, after which MPTP opening (c and e) and the mitochondrial membrane potential (d and $\mathbf{f}$ ) were measured. ( $\mathbf{g}-\mathbf{j})$ Cells treated with $1 \mu \mathrm{M} \mathrm{CsA}$ and $8 \mathrm{mM}$ glutamate were examined and photographed using a reverse-phase microscope $(\mathbf{g})$, and cell viability was analyzed using the MTT assay (h). Scale bar, $100 \mu \mathrm{m}$. The percentages of cells undergoing autophagy and apoptosis and cell cytotoxicity were measured using flow cytometry with acridine orange and annexin V/PI staining (i) and the LDH release assay (j), respectively. Glu, glutamate; SB, SB216763. Data are presented as mean \pm S.E.M. ( $n=3$ /group; 6/group in the MTT assay). ${ }^{* *} P<0.01$ versus each respective control. ${ }^{\# \#} P<0.01$ versus each respective glutamate group, one-way ANOVA

and Use Committee of Taipei Medical University. The animals were anesthetized using intraperitoneal injections of Zoletil 50 (Tiletamine hydrochloride and Zolazepam hydrochloride, $50 \mathrm{mg} / \mathrm{ml} / \mathrm{kg}$; VIRBAC Laboratories, Carros, France) and Rompun (Xylazine, $20 \mathrm{mg} / \mathrm{ml} / \mathrm{kg}$; Bayer AG, Leverkusen, Germany). TBI was induced at the left cortex by using a TBI 0310 Impactor with a $5 \mathrm{~mm}$ impactor tip at a velocity of $5 \mathrm{~m} / \mathrm{s}$ and a depth of $2 \mathrm{~mm}$ for $500 \mathrm{~ms}$ dwell time) (Precision Systems and Instrumentation, LLC, Fairfax, VA, USA). The impact head was centered on the left cortex with its edge $1 \mathrm{~mm}$ away (the closest distance) from the longitudinal suture and the coronal suture, respectively. The animals were anesthetized and sacrificed at $30 \mathrm{~min}$ and 1,4 , and $24 \mathrm{~h}$ after TBI ( $n=3 /$ group). In other cases, the animals received TBI and an immediate application of vehicle or RV $(100 \mathrm{mg} / \mathrm{kg})$ ( $n=3$ /group) and were then sacrificed $4 \mathrm{~h}$ after TBI. The injured brain region and the intact brain region on the contralateral side were collected, and proteins were extracted for immunoblotting.

Cell culture. The rat astrocyte CTX TNA2 cell line was purchased from American Type Culture Collection (Manassas, VA, USA). Type 1 astrocytes obtained from the frontal cortex tissue of 1-day-old Sprague-Dawley rats were transformed by SV40 to establish the CTX TNA2 cell line. CTX TNA2 cells were maintained in DMEM and supplemented with $10 \%$ fetal bovine serum, 100 units $/ \mathrm{ml}$ penicillin, $100 \mu \mathrm{g} / \mathrm{ml}$ streptomycin, $1 \mathrm{mM}$ sodium pyruvate, and $1 \mathrm{mM}$ nonessential amino acids at $37^{\circ} \mathrm{C}$ in a $5 \% \mathrm{CO}_{2}$ incubator.

Cell viability assay. Cells were seeded in 96-well plates at a density of $8 \times 10^{3}$ cells/well for $24 \mathrm{~h}$ and then subjected to various treatments for the specified periods. Before the end of the treatments, $0.5 \mathrm{mg} / \mathrm{ml} \mathrm{MTT}$ was added to each well for $4 \mathrm{~h}$. The supernatants were carefully aspirated, and the formazan crystals were dissolved in DMSO. Absorbance was measured at $550 \mathrm{~nm}$ by using a Thermo Varioskan Flash reader.

LDH release assay. U87 MG cells were seeded in 96-well plates for $24 \mathrm{~h}$ and then subjected to various treatments for the indicated periods. At the end of the treatments, cell morphology was examined and the cells were photographed using an inverted light microscope (Nikon Eclipse TS 100, Nikon Corporation, Tokyo, Japan). LDH release was measured using a CytoTox 96 Non-Radioactive Cytotoxicity Assay Kit (Promega, Madison, WI, USA) according to the manufacturer's protocol. LDH release induced by the lysis buffer supplied by the manufacturer was set at $100 \%$. 
Detection of AVOs. Autophagy is characterized by the formation and promotion of AVOs. ${ }^{54}$ Flow cytometry with acridine orange staining was used to detect and quantify the AVOs. In acridine orange-stained cells, the cytoplasm and nucleus fluoresce bright green and dim red, whereas acidic compartments fluoresce bright red, as described in a previous study. ${ }^{54}$ Therefore, a change in the intensity of the red fluorescence can be measured to estimate the percentage of their cellular acidic compartment. After treatment with various reagents, $1 \times 10^{5}$ cells were collected in the phenol red-free RPMI 1640 medium. The green (FL-1) and red (FL-3) fluorescence of acridine orange were measured using a flow cytometer with the use of CellQuest software (Becton Dickinson, San Jose, CA, USA). The sum of the upper-left and upper-right quadrants of the cytogram was used to estimate the percentage of cells undergoing autophagy.

Detection of apoptosis. Apoptosis was analyzed using flow cytometry with annexin V/PI double-staining for the detection of membrane events. ${ }^{55}$ In brief, after treatment with various drugs, whole cells were collected in a HEPES buffer containing $10 \mathrm{mM}$ HEPES (pH 7.4), $140 \mathrm{mM} \mathrm{NaCl}$, and $2.5 \mathrm{mM} \mathrm{CaCl}_{2}$. The cells were subsequently stained with annexin $\mathrm{V}(2.5 \mu \mathrm{g} / \mathrm{ml})$ and $\mathrm{PI}(2 \mathrm{ng} / \mathrm{ml})$ for $20 \mathrm{~min}$ and then analyzed on a flow cytometer by using the CellQuest software. The cytogram of the four quadrants was used to distinguish normal (annexin $\mathrm{V}^{-} / \mathrm{PI}^{-}$), early apoptotic (annexin $\mathrm{V}^{+} / \mathrm{PI}^{-}$), late apoptotic (annexin $\mathrm{V}^{+} / \mathrm{PI}^{+}$), and necrotic cells (annexin $\mathrm{V}^{-} / \mathrm{PI}^{+}$). The sum of the early and late apoptotic cells represented the total apoptosis.

Measurement of ROS. The intracellular levels of $\mathrm{H}_{2} \mathrm{O}_{2}$ and $\mathrm{O}_{2}^{--}$were detected using the probes DCFH-DA and HEt, respectively. DCFH-DA and HEt were oxidized by $\mathrm{H}_{2} \mathrm{O}_{2}$ and $\mathrm{O}_{2}^{--}$and subsequently emitted green and red fluorescence, respectively. The DHR123 probe can enter the mitochondria, and the green fluorescence represents the mitochondrial $\mathrm{H}_{2} \mathrm{O}_{2}$ level. ${ }^{56}$ Glioma cells were collected at specified time points after various treatments. After trypsinization, the cells were resuspended with PBS and stained with $10 \mu \mathrm{M}$ DCFH-DA, $5 \mu \mathrm{M} \mathrm{HEt}$, or $5 \mu \mathrm{M}$ DHR123 for $30 \mathrm{~min}$ at $37^{\circ} \mathrm{C}$ in the dark. Fluorescence was measured on a flow cytometer by using the CellQuest software. The percentage of increase in fluorescence peaks was used to estimate the level of ROS production.

Measurement of $\Delta \Psi \mathrm{m}$. JC-1, a lipophilic cationic fluorescence dye with the ability to enter mitochondria, was used as an indicator of mitochondrial membrane potential $(\Delta \Psi \mathrm{m}){ }^{57}$ After treatment with glutamate, cells were stained with $5 \mu \mathrm{g} / \mathrm{ml}$ $\mathrm{JC}-1$ for $30 \mathrm{~min}$ at $37^{\circ} \mathrm{C}$ in the dark. The cells were trypsinized and collected in $0.5 \mathrm{ml} \mathrm{PBS}$, and the fluorescence of JC-1 was detected using a flow cytometer. The percentage of the upper-left quadrant was regarded as cells with normal $\Delta \Psi \mathrm{m}$.

Detection of the MPTP opening. The opening of MPTP was examined using calcein $\mathrm{AM}$ staining combined with $\mathrm{CoCl}_{2}$ to detect the mitochondrial calcein fluorescence. ${ }^{58}$ Calcein AM freely passes through the cellular membrane, and the esterases cleave the acetomethoxy group to yield the fluorescent calcein, which is trapped inside the cells. Co-loading of cells with $\mathrm{CoCl}_{2}$ quenches the fluorescence in the cells except that in the mitochondria because $\mathrm{CoCl}_{2}$ cannot cross the mitochondrial membrane. Therefore, when MPTP opens, the mitochondrial calcein is also quenched by $\mathrm{CoCl}_{2}$, which results in a reduction in fluorescence. At the end of treatments, cells were trypsinized and incubated at $37^{\circ} \mathrm{C}$ in $1 \mathrm{ml} \mathrm{HBSS} / \mathrm{Ca}$ with $1 \mu \mathrm{M}$ calcein $\mathrm{AM}$ and $5 \mathrm{mM} \mathrm{CoCl}_{2}$ for $20 \mathrm{~min}$. After incubation, mitochondrial calcein fluorescence was measured using flow cytometry.

Immunoblotting. Cells were lysed using a lysis buffer (25 mM HEPES, 1.5\% Triton X-100, $0.1 \%$ SDS, $0.5 \mathrm{M} \mathrm{NaCl}, 5 \mathrm{mM}$ EDTA, and $0.1 \mathrm{mM}$ sodium deoxycholate) containing a protease inhibitor cocktail. The concentrations of protein in total cellular extracts were measured using a Bio-Rad protein assay dye reagent, and equal amounts of proteins from each group were separated using SDS-PAGE and then transferred to PVDF membranes. Membranes were incubated with a $5 \%$ skim milk solution (blocking solution) for $1 \mathrm{~h}$, and subsequently incubated with the indicated primary antibodies at $4{ }^{\circ} \mathrm{C}$ for $16 \mathrm{~h}$. Membranes were probed with appropriate HRP-conjugated secondary antibodies for $1 \mathrm{~h}$ at room temperature. Immunoreactive proteins were detected by incubating the membranes with an enhanced chemiluminescence reagent (SuperSignal West Pico Chemiluminescent Substrate, Pierce Biotechnology, Rockford, IL, USA) and subsequently exposed to X-ray films (FUJIFILM Corporation, Tokyo, Japan).
The densities of bands were determined using the Gel-Pro Analyzer densitometry software (Media Cybernetics, Silver Spring, MD, USA).

Knockdown of GSK-3 $\beta$. CTX TNA2 cells were transfected with siRNA by using Lipofectamine RNAimax reagent (Invitrogen, San Diego, CA, USA) according to the manufacturer's instructions. In brief, the cells were incubated with the Lipofectamine RNAimax reagent and $100 \mathrm{nM}$ siRNAs for $6 \mathrm{~h}$; the medium was then replaced with fresh medium, and the cells were incubated for a further $42 \mathrm{~h}$. The transfected cells were treated with $8 \mathrm{mM}$ glutamate for $48 \mathrm{~h}$ and analyzed as indicated in the experiments. Silencer validated siRNAs targeting GSK-3 $\beta$ (sense siRNA strand, 5'-GGACAAGCGAUUUAAGAACTT-3'; antisense siRNA strand, 5'-GUUCUUAAAUCGCUUGUCCTG-3') and control siRNA (Cat. No. 12935-300) were obtained from Invitrogen.

Overexpression of GSK-3 $\beta$. CTX TNA2 cells were seeded into six-well plates and transfected with $2 \mu \mathrm{g}$ pcDNA3 or GSK-3 $\beta$-S9A dominant active plasmid by using the Lipofectamine 2000 reagent (Invitrogen) according to the manufacturer's protocol. After transfection, cells were treated with $8 \mathrm{mM}$ glutamate for $48 \mathrm{~h}$, and cell viability and the percentages of cells undergoing autophagy and apoptosis were determined.

Statistical analysis. Data are presented as mean \pm S.E.M. Statistical analysis was performed using Student's $t$-test (for two groups) or using a oneway analysis of variance (ANOVA) followed by Duncan's multiple-range test (for three or more groups). A $P$-value $<0.05$ was considered statistically significant.

\section{Conflict of Interest}

The authors declare no conflict of interest.

Acknowledgements. This work was supported by grants from Cathay General Hospital (101CGH-TMU-05) and the National Science Council (NSC99-2320-B08-008-MY3) to CMS.

1. Nolan S. Traumatic brain injury: a review. Crit Care Nurs Q 2005; 28: 188-194.

2. Maas Al, Stocchetti N, Bullock R. Moderate and severe traumatic brain injury in adults. Lancet Neurol 2008; 7: 728-741.

3. Bell JD, Ai J, Chen Y, Baker AJ. Mild in vitro trauma induces rapid Glur2 endocytosis, robustly augments calcium permeability and enhances susceptibility to secondary excitotoxic insult in cultured Purkinje cells. Brain 2007; 130: 2528-2542.

4. Zhang YB, Li SX, Chen XP, Yang L, Zhang YG, Liu R et al. Autophagy is activated and might protect neurons from degeneration after traumatic brain injury. Neurosci Bull 2008; 24: 143-149.

5. Molz S, Decker H, Dal-Cim T, Cremonez C, Cordova FM, Leal RB et al. Glutamate-induced toxicity in hippocampal slices involves apoptotic features and p38 MAPK signaling. Neurochem Res 2008; 33: 27-36.

6. Smith JS, Fulop ZL, Levinsohn SA, Darrell RS, Stein DG. Effects of the novel NMDA receptor antagonist gacyclidine on recovery from medial frontal cortex contusion injury in rats. Neural Plast 2000; 7: 73-91.

7. Leon R, Wu H, Jin Y, Wei J, Buddhala $\mathrm{C}$, Prentice $\mathrm{H}$ et al. Protective function of taurine in glutamate-induced apoptosis in cultured neurons. J Neurosci Res 2009; 87: 1185-1194.

8. Ray SK, Karmakar S, Nowak MW, Banik NL. Inhibition of calpain and caspase-3 prevented apoptosis and preserved electrophysiological properties of voltage-gated and ligand-gated ion channels in rat primary cortical neurons exposed to glutamate. Neuroscience 2006; 139: $577-595$.

9. Matute C, Domercq M, Sánchez-Gómez MV. Glutamate-mediated glial injury: mechanisms and clinical importance. Glia 2006; 53: 212-224.

10. Rosin C, Bates TE, Skaper SD. Excitatory amino acid induced oligodendrocyte cell death in vitro: receptor-dependent and -independent mechanisms. J Neurochem 2004; 90: 1173-1185.

11. Chen Y, Swanson RA. Astrocytes and brain injury. J Cereb Blood Flow Metab 2003; 23: 137-149.

12. Forde JE, Dale TC. Glycogen synthase kinase 3: a key regulator of cellular fate. Cell Mol Life Sci 2007; 64: 1930-1944.

13. Grimes CA, Jope RS. The multifaceted roles of glycogen synthase kinase 3beta in cellular signaling. Prog Neurobiol 2001; 65: 391-426.

14. Gould TD, Zarate CA, Manji HK. Glycogen synthase kinase-3: a target form novel bipolar disorder treatments. J Clin Psychiatry 2004; 65: 10-21.

15. Emamian ES, Hall D, Birnbaum MJ, Karayiorgou M, Gogos JA. Convergent evidence for impaired AKT1-GSK3beta signaling in schizophrenia. Nat Genet 2004; 36: 131-137. 
16. Bhat RV, Budd SL. GSK3beta signaling: casting a wide net in Alzheimer's disease Neurosignals 2002; 11: 251-261.

17. Pap M, Cooper GM. Role of glycogen synthase kinase-3 in the phosphatidylinostiol 3-kinase/Akt cell survival pathway. J Biol Chem 1998; 273: 19929-19932.

18. Shin SY, Chin BR, Lee YH, Kim JH. Involvement of glycogen synthase kinase-3beta in hydrogen peroxide-induced suppression of Tcf/Lef-dependent transcriptional activity. Cell Signal 2006; 18: 601-607.

19. Wang SH, Shih YL, Kuo TC, Ko WC, Shih CM. Cadmium toxicity toward autophagy through ROS-activated GSK-3beta in mesangial cells. Toxicol Sci 2009; 108: 124-131.

20. Cucciolla V, Borriello A, Oliva A, Galletti P, Zappia V, Ragione FD. Resveratrol: from basic science to the clinic. Cell Cycle 2007; 6: 2495-2510.

21. Saiko P, Szakmary A, Jaeger W, Szekeres T. Resveratrol and its analogs: defense agains cancer, coronary disease and neurodegenerative maladies or just a fad? Mutat Res 2008; 658: $68-94$

22. Wang $Q$, Xu J, Rottinghaus GE, Simonyi A, Lubahn D, Sun GY et al. Resveratrol protects against global cerebral ischemic injury in gerbils. Brain Res 2002; 958: 439-447.

23. Karmarkar SW, Bottum KM, Krager SL, Tischkau SA. ERK/MAPK is essential for endogenous neuroprotection in SCN2.2 cells. PLoS One 2011; 6: e23493.

24. Zhao Y, Chen G, Zhang W, Xu N, Zhu JY, Jia J et al. Autophagy regulates hypoxia-induced osteoclastogenesis through the HIF-1 $\alpha / B N I P 3$ signaling pathway. J Cell Physiol 2011; 227: 639-648.

25. Zschocke J, Zimmermann N, Berning B, Ganal V, Holsboer F, Rein T. Antidepressant drugs diversely affect autophagy pathways in astrocytes and neurons-dissociation from cholesterol homeostasis. Neuropsychopharmacol 2011; 36: 1754-1768.

26. Zhang X, Li L, Chen S, Yang D, Wang Y, Zhang X et al. Rapamycin treatment augments motor neuron degeneration in SOD1(G93A) mouse model of amyotrophic lateral sclerosis. Autophagy 2011; 7: 412-425.

27. Pan C, Gupta A, Prentice H, Wu JY. Protection of taurine and granulocyte colonystimulating factor against excitotoxicity induced by glutamate in primary cortical neurons. J Biomed Sci 2010; 1: S18.

28. Liu $\mathrm{CL}$, Chen $\mathrm{S}$, Dietrich $\mathrm{D}, \mathrm{Hu} B \mathrm{BR}$. Changes in autophagy after traumatic brain injury. J Cereb Blood Flow Metab 2008; 28: 674-683.

29. Kim H, Choi J, Ryu J, Park SG, Cho S, Park BC et al. Activation of autophagy during glutamate-induced HT22 cell death. Biochem Biophys Res Commun 2009; 388: 339-344.

30. Chen Z, Lu T, Yue X, Wei N, Jiang Y, Chen M et al. Neuroprotective effect of ginsenoside Rb1 on glutamate-induced neurotoxicity: with emphasis on autophagy. Neurosci Lett 2010; 482: 264-268

31. Chen HC, Fong TH, Lee AW, Chiu WT. Autophagy is activated in injured neurons and inhibited by methylprednisolone after experimental spinal cord injury. Spine 2012; 37 470-447.

32. Luo CL, Li BX, Li QQ, Chen XP, Sun YX, Bao HJ et al. Autophagy is involved in traumatic brain injury-induced cell death and contributes to functionaloutcome deficits in mice. Neuroscience 2011; 184: 54-63.

33. Hisano K, Watanabe M, Morimoto $\mathrm{Y}$. Protective effects of the free radical scavenger edaravone against glutamate neurotoxicity in nearly pure neuronal culture. J Anesth 2009 ; 23: 363-369.

34. Cheng HY, Hsieh MT, Wu CR, Tsai FH, Lu TC, Hsieh CC et al. Schizandrin protects primary cultures of rat cortical cells from glutamate-induced excitotoxicity. J Pharmacol Sci 2008; 107: 21-31

35. Ates O, Cayli S, Altinoz E, Gurses I, Yucel N, Sener M et al. Neuroprotection by resveratrol against traumatic brain injury in rats. Mol Cell Biochem 2007; 294: 137-144.

36. Liu C, Shi Z, Fan L, Zhang C, Wang K, Wang B. Resveratrol improves neuron protection and functional recovery in rat model of spinal cord injury. Brain Res 2011; 1374: 100-109.

37. Armour SM, Baur JA, Hsieh SN, Land-Bracha A, Thomas SM, Sinclair DA. Inhibition of mammalian S6 kinase by resveratrol suppresses autophagy. Aging 2009; 1: 515-528.

38. Alayev A, Sun Y, Snyder RB, Berger SM, Yu JJ, Holz MK. Resveratrol prevents rapamycininduced upregulation of autophagy and selectively induces apoptosis in TSC2-deficien cells. Cell Cycle 2014; 13: 371-382.

39. Jeong JK, Moon MH, Bae BC, Lee YJ, Seol JW, Kang HS et al. Autophagy induced by resveratrol prevents human prion protein-mediated neurotoxicity. Neurosci Res 2012; 73 99-105.

40. Lv XC, Zhou HY. Resveratrol protects $\mathrm{H} 9 \mathrm{c} 2$ embryonic rat heart derived cells from oxidative stress by inducing autophagy: role of p38 mitogen-activated protein kinase. Can J Physiol Pharmacol 2012; 90: 655-662.

41. Chen ML, Yi L, Jin X, Liang XY, Zhou Y, Zhang T et al. Resveratrol attenuates vascula endothelial inflammation by inducing autophagy through the CAMP signaling pathway. Autophagy 2013; 9: 2033-2045.

42. Lee KY, Koh SH, Noh MY, Park KW, Lee YJ, Kim SH. Glycogen synthase kinase-3beta activity plays very important roles in determining the fate of oxidative stress-inflicted neuronal cells. Brain Res 2007; 1129: 89-99.
43. Wu Y, Shang Y, Sun S, Liang H, Liu R. Erythropoietin prevents PC12 cells from 1-methyl-4phenylpyridinium ion-induced apoptosis via the Akt/GSK-3beta/caspase-3 mediated signaling pathway. Apoptosis 2007; 12: 1365-1375.

44. Petit-Paitel A, Brau F, Cazareth J, Chabry J. Involvment of cytosolic and mitochondrial GSK-3beta in mitochondrial dysfunction and neuronal cell death of MPTP/MPP-treated neurons. PLoS One 2009; 4: e5491.

45. Obame FN, Plin-Mercier C, Assaly R, Zini R, Dubois-Randé JL, Berdeaux A et al. Cardioprotective effect of morphine and a blocker of glycogen synthase kinase 3 beta, SB216763 [3-(2,4-dichlorophenyl)-4(1-methyl-1H-indol-3-yl)-1H-pyrrole-2,5-dione], via inhibition of the mitochondrial permeability transition pore. J Pharmacol Exp Ther 2008; 326: 252-258.

46. Yao LL, Huang XW, Wang YG, Cao YX, Zhang CC, Zhu YC. Hydrogen sulfide protects cardiomyocytes from hypoxia/reoxygenation-induced apoptosis by preventing GSK-3beta-dependent opening of mPTP. Am J Physiol Heart Circ Physiol 2010; 298: $\mathrm{H} 1310-\mathrm{H} 1319$

47. Liu H, Mi S, Li Z, Hua F, Hu ZW. Interleukin 17A inhibits autophagy through activation of PIK3CA to interrupt the GSK3B-mediated degradation of BCL2 in lung epithelial cells. Autophagy 2013; 9: 730-742.

48. Parr C, Carzaniga R, Gentleman SM, Van Leuven F, Walter J, Sastre M. Glycogen synthase kinase 3 inhibition promotes lysosomal biogenesis and autophagic degradation of the amyloid- $\beta$ precursor protein. Mol Cell Biol 2012; 32: 4410-4418

49. Wang $\mathrm{H}$, Zhou $\mathrm{H}$, Zou Y, Liu Q, Guo C, Gao G et al. Resveratrol modulates angiogenesis through the GSK3 $/ \beta$-catenin/TCF-dependent pathway in human endothelial cells. Biochem Pharmacol 2010; 80: 1386-1395.

50. Pozo-Guisado E, Lorenzo-Benayas MJ, Fernández-Salguero PM. Resveratrol modulates the phosphoinositide 3-kinase pathway through an estrogen receptor alpha-dependent mechanism: relevance in cell proliferation. Int J Cancer 2004; 109 : 167-173.

51. Shin SM, Cho IJ, Kim SG. Resveratrol protects mitochondria against oxidative stress through AMP-activated protein kinase-mediated glycogen synthase kinase-3beta inhibition downstream of poly(ADP-ribose)polymerase-LKB1 pathway. Mol Pharmacol 2009; 76: 884-895.

52. Varamini B, Sikalidis AK, Bradford KL. Resveratrol increases cerebral glycogen synthase kinase phosphorylation as well as protein levels of drebrin and transthyretin in mice: an exploratory study. Int J Food Sci Nutr 2014; 65: 89-96.

53. Zamin LL, Dillenburg-Pilla $P$, Argenta-Comiran R, Horn AP, Simão F, Nassif $M$ et al. Protective effect of resveratrol against oxygen-glucose deprivation in organotypic hippocampal slice cultures: Involvement of PI3-K pathway. Neurobiol Dis 2006; 24: 170-182.

54. Kanazawa T, Bedwell J, Kondo Y, Kondo S, Germano IM. Inhibition of DNA repair for sensitizing resistant glioma cells to temozolomide. J Neurosurg 2003; 99: 1047-1052.

55. Pietra G, Mortarini R, Parmiani G, Anichini A. Phases of apoptosis of melanoma cells, but not of normal melanocytes, differently affect maturation of myeloid dendritic cells. Cancer Res 2001; 61: 8218-8226.

56. Thévenod F, Friedmann JM. Cadmium-mediated oxidative stress in kidney proximal tubule cells induces degradation of $\mathrm{Na}^{+} / \mathrm{K}^{+}$-ATPase through proteasomal and endo-/lysosomal proteolytic pathways. FASEB J 1999; 13: 1751-1761.

57. Cossarizza M, Baccarani-Contri G, Kalashnikova C, Franceschi C. A new method for the cytofluorimetric analysis of the mitochondrial membrane potential using the $\mathrm{J}$-aggregate forming lipophilic cation $5,5^{\prime}, 6,6^{\prime}$-tetrachloro-1,1',3,3'-tetraethylbenzimidazolcarbocyanine iodide (JC-1). Biochem Biophys Res Commun 1993; 197: 40-45.

58. Petronilli V, Miotto G, Canton M, Brini M, Colonna R, Bernardi $P$ et al. Transient and long-lasting openings of the mitochondrial permeability transition pore can be monitored directly in intact cells by changes in mitochondrial calcein fluorescence. Biophys J 1999; 76 : 725-734

(1) $(9)$ Cell Death and Disease is an open-access journal (1) published by Nature Publishing Group. This work is licensed under a Creative Commons Attribution-NonCommercialNoDerivs 3.0 Unported License. The images or other third party material in this article are included in the article's Creative Commons license, unless indicated otherwise in the credit line; if the material is not included under the Creative Commons license, users will need to obtain permission from the license holder to reproduce the material. To view a copy of this license, visit http://creativecommons.org/licenses/ by-nc-nd/3.0/ 